\title{
Création de la revue Connexe
}

Transitions, la revue publiée depuis 1993 par l'Université libre de Bruxelles et depuis 2000 en partenariat avec l'Université de Genève, n'est plus. Plus de vingt ans se sont écoulés depuis sa création. Durant ces deux décennies, le paradigme de la « transition » a été amplement convoqué pour analyser les profondes transformations auxquelles a été sujet l'ancien espace communiste après l'effondrement du mur de Berlin. De nombreuses études ont rendu compte de la complexité de ces transitions à l'œuvre, ainsi que des difficultés posées par la nécessité, pour les chercheurs, de travailler « en temps réel», en pleine tourmente institutionnelle, économique, sociale, politique et identitaire. La revue Transitions a quant à elle largement contribué au développement d'une réflexion sur les enjeux des changements en cours.

« Reconstruire le bateau en pleine mer » fait partie des images les plus souvent utilisées pour évoquer une des contraintes majeures pesant sur le processus de transition. Qu'en est-il aujourd'hui de cette, ou plutôt de ces reconstructions ? Des précautions s'imposent ici. Les différents États issus de l'éclatement du bloc communiste étaient porteurs d'héritages divers. Leurs trajectoires se sont dès lors rapidement singularisées : une partie des anciennes «démocraties populaires » a rejoint l'Union européenne, une autre en prend le chemin. D'autres États, souvent issus de la désintégration de l'URSS, empruntent des voies différentes, comme autant de navires suivant des caps fort divers. Cet espace gigantesque est encore en cours de remodelage. Soumis à des bouleversements majeurs, il témoigne d'évolutions diverses, comme en atteste la multiplicité des types de régimes politiques, mais aussi la diversité des cultures, des histoires et des sociétés mobilisées par cette recomposition.

Dès lors, il devient difficile, voire hasardeux, de rassembler sous un même terme des évolutions aussi disparates. En outre, selon quels critères et modalités peut-on affirmer qu'une transition qui se voulait démocratique est achevée ou a été dévoyée ? 
La notion de transition nous semble dorénavant non seulement insuffisante, mais souvent inopérante pour rendre compte de cette diversité.

\section{Une revue pluridisciplinaire}

Fin de Transitions, place à Connexe : les espaces postcommunistes en question(s). Ce titre désigne à lui seul l'ampleur de nos ambitions : mettre en relation des disciplines et objets de recherche voisins, tisser des liens entre des domaines et des espaces " connexes ", saisir à la fois le multiple et le commun, la singularité et l'ensemble, le présent et le passé, le régional et le transnational, la revue s'intéressant à un large espace géographique, qui intègre les anciennes « démocraties populaires » et les anciennes Républiques de l’Union soviétique.

La recherche consacrée aux espaces postcommunistes a connu tout au long de ces vingt dernières années de profonds renouvellements épistémologiques. Selon les intérêts, les approches, les supports théoriques, les disciplines, une attention particulière a été accordée tantôt aux trajectoires de la consolidation démocratique, de l'européanisation, tantôt aux acteurs sociaux, tantôt aux contextes historiques, tantôt, encore, aux dynamiques internationales, ou enfin, aux cas « nationaux » et aux analyses transnationales. Le recours à la comparaison comme mode de questionnement a été fréquent, sans pour autant tomber dans le piège de l'appauvrissement des cas étudiés. Les questions restent nombreuses. Qu'en est-il de l'organisation des pouvoirs à différentes échelles ? Comment les acteurs reconfigurent-ils, aujourd'hui, leur intervention dans les champs du social, du politique, de l'économique, mais aussi aux niveaux culturel et artistique ? Les notions de parti politique, de classe et d'entreprise ont-elles évolué, alors que la place qui leur revient constitutionnellement, juridiquement ou socialement a été radicalement modifiée ? Quels sont les effets de l'européanisation, ou plutôt comment les sociétés concernées s'adaptent-elles à l'intégration européenne ? Quel rôle accorder au temps long de l'histoire pour analyser, plus de vingt ans après l'éclatement de l'Union soviétique, la portée et les impacts des conflits armés qui ont éclaté dans toute la zone qui nous occupe ? Comment comprendre les «guerres de mémoire » qui travaillent les élites et les sociétés de certains États issus de l'ancien monde communiste, ainsi que la réécriture dont l'histoire y fait l'objet? Les analyses transversales sont-elles appropriées pour mieux comprendre le lien entre des phénomènes globaux et la construction d'espaces nationaux et/ou régionaux ? Quel rôle ont joué les diverses formes d'expressions artistiques et leur appropriation populaire, notamment la littérature, dans la désintégration du bloc communiste, et quelles places occupent-elles aujourd'hui?

Tenter d'autres parallèles, d'autres rapprochements, dans une pratique scientifique marquée par la volonté de croiser les analyses de spécialistes dans les disciplines des sciences humaines et sociales, tel sera l'un des principaux objectifs de la revue 
Connexe. Celle-ci accueillera des articles traitant de science politique, d'histoire, de sociologie, d'économie, d'anthropologie, de géographie, de culture, de littérature et d'art. Enfin, même si, nourrie par les réflexions théoriques qui ont marqué l'histoire et les sciences sociales ces dernières décennies, la revue accorde une large place aux débats qui ont lieu au sein de cette vaste aire, elle accueille également des recherches qui étudient l'espace postcommuniste dans ses rapports, ses interactions et ses connexions avec d'autres aires culturelles.

Éditée par l'Institut de Sociologie de l'Université libre de Bruxelles et par le Global Studies Institute de l'Université de Genève, la revue Connexe paraît à un rythme de deux numéros simples ou un numéro double par année. La principale langue de publication est le français, mais des articles en anglais peuvent être proposés. Les textes sont soumis à une double évaluation anonyme par des pairs, selon les normes des revues scientifiques. Outre la publication de numéros consacrés à des dossiers thématiques précis ou à une problématique générale, la revue publie des comptes rendus d'ouvrages et des varia.

Le Comité de rédaction 